\title{
The Westminster Hospital coronary unit - experience with 260 patients admitted consecutively with a diagnosis of acute myocardial infarction
}

\author{
J. G. B. Thurston \\ M.B., M.R.C.P. \\ Medical Registrar to the Coronary Intensive Care Unit, \\ Westminster Hospital, London, S.W.1.
}

\section{Summary}

In successive years since the opening of a Coronary Care Unit at Westminster Hospital the mortality has been 26 and $20 \%$ and for the first 4 months of $1968,5 \cdot 3 \%$. Overall mortality for 260 patients was $20 \%$.

Resuscitation has been successful in $59 \%$ of cardiac arrests within the unit and in $27 \%$ of those outside the unit caused by myocardial infarction. Seventeen patients left hospital alive and well who presumably would not have survived had they been treated at home.

Given efficient nursing staff and a resuscitation team, there can no longer be any justification for the treatment of patients with myocardial infarction anywhere other than in a coronary care unit, where such facilities are made available, providing admission is arranged within 3 days of the infarcting episode. The disadvantage of an ambulance journey to a patient with a recent infarct after this period of time may outweigh the advantage incurred by the coronary care unit.

The Peel Coronary Prognostic Index remains a very useful guide to prognosis in spite of this author's attempts to demonstrate any inaccuracies in its predictions.

A high (20\%) 'misdiagnosis' rate must be accepted if some patients with bona fide myocardial infarction are not to be excluded from the unit.

The occurrence of 435 deaths reported to Her Majesty's Coroner for Westminster in the relevant period due to myocardial infarction suggests that the time may be ripe for a 'flying squad' resuscitation service in London.

\section{Introduction}

Since the setting up of the first intensive care unit for the treatment of patients with acute myocardial infarction (Day, 1963a), many reports of results obtained in such units have been published (Brown et al., 1963; Day, 1963b, 1965; Julian, Valentine \&
Miller, 1964a, b; Robinson, 1965; Goble, Sloman \& Robinson, 1966; Restieaux et al., 1967; Lawrie et al., 1967; Lown et al., 1967; Thomas, Jewitt \& Shillingford, 1968; Pentecost \& Mayne, 1968). Before the inception of these units the mortality of the disease was between 30 and $40 \%$. Results in general have shown that mortality can be reduced to around $20 \%$ when patients are admitted to a coronary intensive care unit. Some units report an even greater reduction (Brown et al., 1963, 18\%; Day, 1965, 15.9\%; Restieaux et al., 1967, 14\%; Lawrie et al., 1967, $17.5 \%$ ). This improvement in mortality is almost entirely due to the prompt recognition and reversal of life-threatening arrhythmias, the most notable being ventricular fibrillation. Units have been opened in many general hospitals and the practice of monitoring patients with an acute myocardial infarction is rapidly attaining the status of a routine.

Pantridge \& Geddes (1967) have logically extended this process by taking equipment to the patient, thus bringing forward in time the monitoring of the electrocardiogram in the early period following the infarction when the patient is most vulnerable.

The purpose of this report is to draw attention to another coronary intensive care unit, to detail the encouraging results obtained, to assess further the Coronary Prognostic Index described by Peel $e t$ al. (1962) and to emphasize the benefit of treating patients in such units as against care in the $h$ ome or in the general medical wards, providing that the patient is admitted soon after the episode.

\section{Layout and methods}

The unit is on the second floor of the $h$ sspital and comprises three beds and two hyperbaric oxygen beds. It is perhaps rather far from the Accident and Emergency Department which is on the ground floor, but is close to the general medical wards to where the patients are subsequently transferred. In addition to being employed in some patients with coronary thrombosis, the hyperbaric oxygen chambers are used for a wide variety of general medical conditions. 
Their use in acute myocardial infarction is the subject of a separate report (Ashfield, 1969).

The unit is staffed by state-registered nurses assisted by nurses under training who are attached for several weeks at a time as part of their general training. The nurses have become skilled in the detection and diagnosis of arrhythmias and seek medical assistance immediately when changes in the patient's condition occur. Cardiac arrest is treated either by the full-time medical registrar attached to the unit (the author, who was appointed on 1 January 1967) or by a resident team consisting of duty anaesthetic, surgical and cardiac registrars who also deal with cardiac arrests elsewhere in the hospital. No facilities are provided for a resident doctor in the unit at night.

In case of arrest, the nurse present sounds a loud alarm bell outside the unit by means of a switch close to hand. Nurses outside the unit then ring through to an emergency telephone and the resuscitation team is summoned. During the day medical staff are normally present in the unit and prompt defibrillation may obviate the need to call the emergency team.

All patients admitted to Westminster Hospital with a provisional diagnosis of acute myocardial infarction are sent to the unit. The normal sources are the local general practitioners, the Emergency Bed Service, the Accident and Emergency Department, Out-Patients Departments and the general wards of the hospital. No age limit is set. The provisional diagnosis is made on a history of typical chest pain and/or an electrocardiogram compatible with a diagnosis of acute myocardial infarction. The patient is not accepted into the unit if the episode took place more than 3 days before presentation unless arrest has just occurred or there is an arrhythmia that merits monitoring. Casualty officers are encouraged to send any patient with a suspicion of this diagnosis to the unit forthwith and they are then transferred to the medical wards if the initial suspicion is not substantiated. This leads to a significant number of patients without infarcts being admitted but represents a safe policy which has been deliberately adopted. In addition to these patients, people with troublesome arrhythmias who need monitoring, those with heart block from other causes and patients who have developed cardiac arrest elsewhere in the hospital are also accepted for admission on account of facilities available in the unit.

Patients are kept in the unit for an average of $5 \frac{1}{2}$ days. This period is extended if no patient presents for admission when one of the present incumbents is due for transfer. If a patient presents for admission before that time, a place is found by moving out whichever patient appears least ill clinically. Thus the bed occupancy is maintained at a maximum and no patient is ever turned away because the unit is full. $₹$

As soon as the patient arrives, he is first connected $\stackrel{\varnothing}{\Omega}$ to an oscilloscope. This has become routine because.. initially the occasional patient would develop cardiac arrest while not connected to an oscilloscope because some other duty had been given priority. This has been emphasized to the nurses. The electrodes used are those described by Fluck \& Burgess (1966) and are fixed to the chest, allowing the patient free use of his limbs unencumbered by monitoring wires. A tape recorder is available at all times and is used to record the patient's electrocardiogram continuously when this is indicated. (Because it is clearly impossible to say when it is indicated in all patients, the practice of recording all electrocardiograms continuously is being adopted.)

A DC defibrillator is kept in the unit, plugged in and turned on, with a cable which is long enough to allow the machine to be wheeled to any bed. This avoids the delay occasionally encountered in seeking a suitable power point, especially when staff unfamiliar with the unit are present.

Apparatus is available for measurement of right heart pressures and cardiac output by the dyedilution technique using a Gilford cuvette, Sanborn computer and Honeywell wide chart recorder. Piped oxygen is supplied to each bed but wall suction is not yet available.

The patient is admitted under the care of the admitting physician of the day and is transferred to one of his beds when discharged from the unit. This ensures continuity of management. The registrar attached to the unit is available for hour-to-hour changes in treatment and the prompt reversal of cardiac arrest. A busy research programme is also in progress. Routine investigations performed include blood count, chest X-ray, full electrocardiogram, enzyme estimations, arterial blood gases with the patient breathing air and serum electrolytes. Blood gas estimations can be rapidly made due to the close proximity of Astrup equipment and the co-operation of the department of chemical pathology who provide staff to operate it.

The constant vigil provided by the nursing staff is regarded as of paramount importance and audible warning devices on the oscilloscope are not used. These devices have been found to go off inappropriately on occasion but, more important, give the nurse in charge a false feeling of security so that she relies on her ears rather than her eyes to detect changes in the patient's condition. To ensure that constant attention is paid to the patients, the heart rate is counted $\frac{1}{2}$-hourly and the number of ectopic beats recorded over a full minute each $\frac{1}{2}-\mathrm{hr}$ by the nurse in charge. Blood pressure recordings are taken hourly initially and the number of recordings either 
increased or decreased according to the patient's progress. The rule has been made that the unit must never be left unattended at any time. All beds have fracture boards placed under the mattress to facilitate effective cardiac massage should this prove necessary.

\section{Treatment}

A treatment schedule has been drawn up with which all admitting physicians have agreed. This was done to produce uniformity of therapy, although opinions on the value of anti-coagulants continue to differ.

\section{Oxygen}

That patients with acute myocardial infarction often have a reduced partial pressure of oxygen in their arterial blood was first pointed out by $\mathrm{McNicol}$ et al. (1965). All patients are given oxygen by M.C. mask at a flow rate of 6 litres/min for at least $48 \mathrm{hr}$. After this time oxygen is given only if the arterial $\mathrm{Po}_{2}$ is still below normal limits when the oxygen is turned off and the patient breathes room air for $20 \mathrm{~min}$.

\section{Pain}

It is regarded as essential to relieve pain and as a result of the writings of Thomas et al. (1965) on morphia, Rees et al. (1967) on pethidine and MacDonald et al. (1967) on heroin, the drug diamorphine has been used exclusively to produce analgesia in as small a dose as is effective, usually $5 \mathrm{mg}$ intramuscularly.

\section{Position in bed}

That position is chosen which the patient finds most comfortable. If there is evidence of hypotension (systolic blood pressure below $85 \mathrm{mmHg}$ ) whether accompanied either by vasoconstriction or vasodilatation, the patient lies flat and the foot of the bed is elevated (see 'Cardiogenic shock', below).

\section{Anti-coagulants}

If anti-coagulants are given, heparin is the drug of choice initially. Whether the drug is given depends on the individual views of the admitting physician. Heparin is given by intravenous infusion in $5 \%$ dextrose, 1 litre/24 hr containing 40,000 units of heparin or, better, by the continuous infusion pump described by Handley (1967) the same dose of heparin being given in a volume of $40 \mathrm{ml}$. Oral therapy with warfarin sodium or phenindione is continued for a variable period according to the physician concerned.

\section{Bradycardia}

If there is a fall in the heart rate below 50 beats $/ \mathrm{min}$ accompanied by evidence of clinical deterioration but with no evidence of heart block, the patient is given atropine sulphate, $0.6 \mathrm{mg}$ intravenously. This is repeated if necessary according to the response to the initial dose. The effects of this have been reported by Thomas \& Woodgate (1966).

\section{Arrhythmias}

(1) Supraventricular tachycardia. If there is a supraventricular tachycardia with a ventricular rate of 120 beats/min or more which is thought to be causing or likely to cause deterioration in the patient's general condition, then the patient is digitalized. That this drug is better avoided if possible has been shown by Balcon, Hoy \& Sowton (1968).

(2) Ventricular extrasystoles. If the incidence of these is greater than $6 / \mathrm{min}$ and remains so over several minutes as assessed on the oscilloscope, or if there is a run of three or more ventricular extrasystoles in succession or if extrasystoles occur on the vulnerable part of the $T$ wave, then lignocaine, $50 \mathrm{mg}$, is injected slowly intravenously. After this an infusion of lignocaine in $5 \%$ glucose is given at $1 \mathrm{mg} / \mathrm{min}$ for $48 \mathrm{hr}$ or longer if necessary, depending on the electrocardiogram when the infusion is halted (Jewitt, Kishon \& Thomas, 1968; Spracklen et al., 1968; Kimball \& Killip, 1968).

(3) Ventricular tachycardia. This is best treated by an electric shock from the DC defibrillator. If the patient is not unconscious and cannot immediately undergo general anaesthesia because of a full stomach and the risk of inhaling vomitus during induction, then lignocaine should be given intravenously as above.

A DC shock is the treatment of choice for any fast arrhythmia which causes loss of consciousness as a result of inadequate cerebral perfusion.

(4) Complete heart block. The development of complete (grade 3) heart block is, if present for more than a few minutes, treated by the intravenous injection of $100 \mathrm{mg}$ hydrocortisone hemisuccinate while preparations are made for the insertion of an endocardial pacing catheter. If the heart block persists for more than $30 \mathrm{~min}$, a pacing electrode is inserted into the right ventricular cavity from an arm vein, under radiographic control, so that pacing may be applied if needed. Internal pacing is only commenced if the cardiac output is inadequate, if the ventricular rate falls progressively or if the patient's consciousness becomes clouded (Scott et al., 1967; Lassers \& Julian, 1968).

\section{Cardiogenic shock}

Not only have the results of treatment of this condition been unsatisfactory in general, but the 
very definition of the syndrome does not seem to be agreed universally. In this unit a patient is said to have cardiogenic shock when pallor, sweating, cold extremities and hypotension (systolic blood pressure below $80 \mathrm{mmHg}$ ) accompany signs of cerebral dysfunction. The latter may vary from mild confusion to frank unconsciousness. Many of these patients have been selected for treatment with hyperbaric oxygen and are the subject of a separate report (Ashfield \& Gavey, 1969).

\section{Cardiac failure}

Treatment of pulmonary oedema is along conventional lines, using diuretics initially and digitalis if control is not achieved with these drugs.

Drugs of all types have been avoided throughout where possible and no drugs are given routinely or without strong indication. The above details as set down for therapy have been sent to all doctors who make use of the unit for their patients so that conformity of treatment may be attained. This enables particular techniques of treatment to be the better assessed.

\section{Coronary prognostic index (Peel et al., 1962)}

This method of assessing prognosis on the day on which the acute myocardial infarction occurs has been used throughout in this series. A score is given to the patients on the basis of age, sex, previous medical history, heart failure, 'shock', electrocardiographic changes and arrhythmias. This score has been correlated with the patients' subsequent progress up to death or discharge from hospital. A longterm follow-up has not yet been analysed.

\section{Results}

A table giving details of the number of patients admitted to the unit in each year is shown below.

\begin{tabular}{lrrcr}
\hline & 1966 & 1967 & 1968 & All \\
\hline Total no. of patients admitted & 124 & 147 & 59 & 330 \\
Patients with proven infarction & 93 & 121 & 51 & 265 \\
'Misdiagnosis' rate $(\%)$ & 25 & 18 & 14 & 20 \\
\hline
\end{tabular}

Figures for 1968, first 4 months only.

The policy outlined earlier resulted in sixty-five patients being admitted to the unit in whom a diagnosis of acute myocardial infarction was not later substantiated. The true diagnosis of these patients was as follows:

$\begin{array}{lr}\text { Ischaemic heart disease } & 29 \\ \text { Left ventricular failure } & 7 \\ \text { Cause undetermined } & 5 \\ \text { Arrhythmia } & 4 \\ \text { Oesophageal reflux } & 3 \\ \text { 'Syncope' } & 3 \\ \text { Symptoms of psychogenic origin } & 3\end{array}$

Cardiac arrest elsewhere $\quad 2$

Drug addiction 2

Pulmonary embolus

Aortic dissection

Aortic stenosis

Complete heart block

Post aortic valvotomy

Subarachnoid haemorrhage

Vertebro-basilar insufficiency

The wide variety of medical and surgical conditions in this list reflects not diagnostic ineptitude but the loose acceptance policy of the unit. It underlines the diversity of conditions which may present with chest pain or loss of consciousness with an abnormal electrocardiogram.

\section{Cardiac arrest}

The most striking benefit obtained since the inception of the unit has been in the results of resuscitation in patients who have suffered a cardiac arrest. Resuscitation is deemed to be successful if there is spontaneous return of the circulation and speech in a patient who had been clinically dead. Comparison of the figures for successful resuscitation in the unit with the figures for resuscitation outside the unit emphasise the advantage of continuous monitoring and prompt corrective action on the part of trained staff.

\begin{tabular}{lrrrr}
\hline & 1966 & 1967 & 1968 & Ale \\
\hline No. of arrests in the unit & 22 & 40 & 8 & 70 \\
No. corrected & 10 & 26 & 5 & 41 \\
Percentage & 45 & 65 & 62 & 59 \\
No. leaving hospital alive & 4 & 12 & 1 & 17 \\
No. of arrests out of unit & 11 & 16 & 3 & 30 \\
No. corrected & 0 & 6 & 2 & 8 \\
Percentage & 0 & 37 & 66 & 27 \\
\hline
\end{tabular}

Figures for 1968, first 4 months only.

Thus it can be seen that the resuscitation rate within the unit is more than twice what it is for patients with cardiac arrest following acute mycocardial infarction in the hospital as a whole. Seventeen patients left hospital alive and without any evidence of neurological deficit who presumably would not have survived had they been treated at home.

Fig. 1 shows at what stage following the myocardial infarction the arrest occurred. The time of infarction has been taken as the point at which the symptoms started.

\section{Mortality}

The mortality has been assessed on whether the patients are alive or dead at the time of leaving hospital and not whether they leave the unit alive.

The mortality rate in 1966 was $25 \%$. In 1967 it was reduced to $20 \%$ and in the first 4 months of 1968 a 


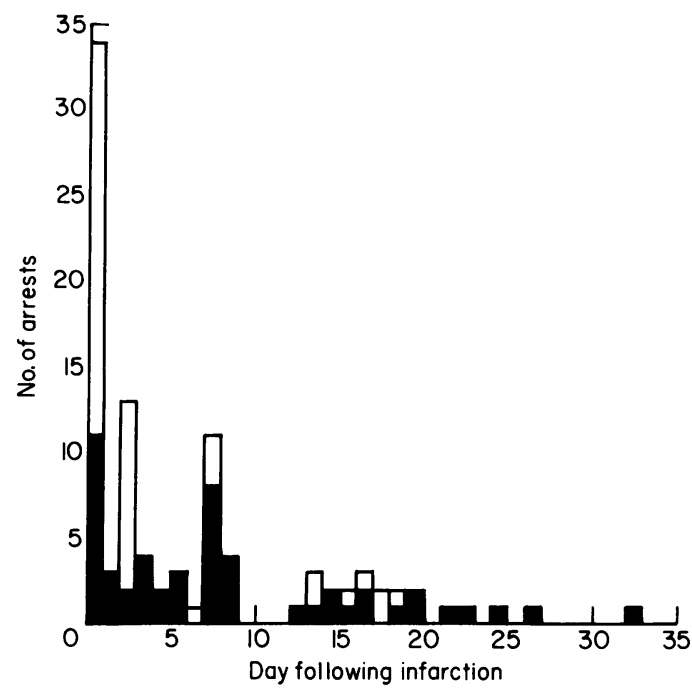

FIG. 1. The stage following myocardial infarction at which arrest occurred. Solid columns, Death; open columns, successful resuscitation.

total of fifty-six patients with acute myocardial infarction passed through the unit with three deaths, a mortality rate of $5.3 \%$. The total mortality rate for the 260 patients was $20 \%$.

\begin{tabular}{lcccr}
\hline & 1966 & 1967 & 1968 & All \\
\hline Total no. of patients & 93 & 121 & 56 & 260 \\
Deaths & 24 & 24 & 3 & 51 \\
Percentage deaths & 26 & 20 & $5 \cdot 3$ & 20 \\
\hline
\end{tabular}

\section{Age}

The mean age of all patients admitted was 59 years, the youngest being 30 and the eldest 84 .

\section{Coronary prognostic index}

The results of applying the prognostic index referred to above are shown in Fig. 2. The end-point for surviving patients is taken as the date on which they are discharged from hospital. The possible range of score on this scale is $0-28$. The higher the score, the worse the prognosis.

\section{Heart failure}

Of the 177 patients admitted since 1 January 1967, fifty-five $(31 \%)$ had frank pulmonary oedema either clinically or radiographically. In addition twelve had clinical evidence of elevated jugular venous pressure and twenty-two had either a third or fourth heart sound as an isolated clinical finding. Nineteen patients had fine crepitations at both bases without radiographic evidence of pulmonary venous congestion or septal lines. The Peel index includes a score for basal crepitations and it is for this reason



Fig. 2. Results of applying prognostic index. Solid columns, Deaths; open columns, live patients.

that this finding has been included. In the absence of left atrial pressure measurements one cannot be sure whether these crepitations represent left ventricular failure or are indicative of pulmonary disease. At any rate, in these nineteen patients, there were no other signs suggestive of heart failure, and the chest $\mathrm{X}$-rays were normal.

\section{Post-mortem examinations}

The post-mortems performed on those patients who died in spite of attempted resuscitation revealed extensive disease of either two or all three of the three main coronary branches supplying the myocardium (right, circumflex and anterior descending) in twenty-seven $(77 \%)$ out of thirty-five autopsies. In no patient was there a single block in an otherwise healthy coronary tree. Two patients had ruptured ventricles, two died of co-existent carcinoma and one patient had undergone a double valve replacement 6 weeks before. One patient had tubular necrosis, one multiple renal abcesses and one a ruptured interventricular septum which had been diagnosed clinically but in whom surgical intervention had not been thought desirable. In sixteen patients permission for post-mortem examination was either not sought or not granted.

\section{Discussion \\ Mortality}

The reduction in mortality since the unit was opened has been encouraging and results obtained 
are similar to those of the many other units whose figures have been published. The concept that no patient should die of ventricular fibrillation has been slow to pervade the attitudes of the junior medical staff and nurses. Good results undoubtedly depend on competent nurses. The doctors attached to the thoracic unit (where the coronary unit is situated) have instituted a course of lectures for nurses working on the unit and this has produced a high degree of skill in the diagnosis of arrhythmias and familiarity with the use of equipment. Nurses are not yet permitted to use the DC defibrillator unlike the practice in some units. Clearly the ideal treatment for ventricular fibrillation is immediate defibrillation by the person who is in attendance and who in this unit is usually a nurse.

The policy adopted in this unit has been that ruptured ventricle is the only medically acceptable cause of death associated with the infarction and that any other cause related to the infarction should have been remediable. This is perhaps a counsel of perfection but has stimulated enthusiastic interest in the welfare of patients with myocardial infarction who, before the introduction of coronary care units, would have been treated more conservatively without electrocardiographic monitoring, sudden death being an accepted hazard.

During the period under review, myocardial infarction accounted for 435 of the cases of sudden death reported to the Westminster coroner and only eighteen of these had a ruptured ventricle. One is not suggesting that 417 of these deaths were reversible as many of these were aged patients and several were found a few hours or even days after death, at a time when resuscitation was not feasible. A leader in the Lancet (23 September 1967, page 665) said: 'to be fully effective intensive care must be backed by a flying squad ambulance service, carrying means of resuscitation'.

Pantridge \& Geddes (1967) have reported on just such a service and one wonders whether a trial service in London where the distance between patient and hospital is small, is not now justified.

The mortality in the $2 \frac{1}{3}$ years has steadily fallen. In the 1st year the unit was staffed only by nurses, in the 2nd year a doctor was appointed to the unit and in the 3rd year the probable benefits of a nurses' training programme are now being seen. These facts account partly, at any rate, for the decline in mortality. The figure for the first 4 months of 1968 , $5.3 \%$, is exceptionally low and it does only cover a short period. One agrees with Pentecost \& Mayne (1968) that a cheaply run unit with nurses only as resident staff can produce good results. If possible, however, it is desirable to have resident medical staff as well.

\section{Resuscitation}

Fig. 1 shows that cardiac arrest is both more likely in the first $24 \mathrm{hr}$ following infarction (first shown by Honey \& Truelove, 1957) and is also more likely to be corrected (Julian et al., 1964a, b; Day, 1965; Goble et al., 1966). Thomas et al. (1968), point out that half their successful resuscitations occurred after the 3rd day. In this unit, on the contrary, $75 \%$ of successful resuscitations occurred before the 3rd day. Given the beds and the staff, it appears that 9 days is the optimal time to keep a patient in the unit. Considerable benefit is gained, however, in monitoring the patient for only $24 \mathrm{hr}$, if there is heavy demand for admission to beds in the unit. Results will only be good: 'when well trained professional personnel utilize sound therapeutic principles with consistency and speed. Monitoring of the electrocardiogram does not per se save lives' (Kimball \& Killip, 1968).

These facts justify the policy of keeping the unit full at all times, moving patients according to progress when a fresh patient presents for admission.

It can be appreciated from Fig. 1 that successful resuscitation in the unit $(59 \%)$ is more than twice as likely as that outside the unit in the hospital in general $(27 \%)$. Like Pentecost, Mayne \& Lamb (1967), one plays less part in resuscitation in the Casualty Department than one would like to, due to the geography of the hospital. These figures make it hard to defend admission of a coronary patient straight to the wards in a hospital where the facilities of a coronary care unit are offered as an alternative; but very hard indeed to justify treating a patient at home where successful resuscitation occurs presumably very rarely. This statement does not apply where coronary occlusion provides a happy release from terminal illness or disabling senility.

A fit 81-year-old grandfather who returned well to his grateful family would no doubt support the policy of the unit to resuscitate at any age having regard in this way to the patient's previous fitness and absence of concomitant illness.

In this unit it is regarded as bad policy to 'move house simply because a fuse has blown', and attempts are, therefore, always made to correct ventricular fibrillation.

One would agree with the principle expressed by Kimball \& Killip (1968): 'Our experience in treating patients with acute myocardial infarction in the Coronary Care Unit has clearly demonstrated that the appropriate, aggressive and skilful use of antiarrhythmic drugs and electrical technics will control life-threatening arrhythmias in most instances'.

As at the Birmingham and Hammersmith units, no reliance is placed on the audible warning systems built into the oscilloscope. 


\section{Peel Coronary Prognostic Index}

One's original purpose in working out the Peel Index for each patient was to test the accuracy of its predictions and possibly to modify it by the inclusion of further details. Reference to Fig. 2 reveals, however, that the index as it stands provides a very reasonable guide to prognosis on the 1st day, and remains a credit to its original authors 6 years later, its main advantage lying in its simplicity. The number of deaths at each score for the index tends to remain constant while the number of patients alive at time of discharge from hospital tends steadily to fall at each score. If one accepts the limitations of the index, it remains a useful guide to prognosis.

\section{Misdiagnosis}

As stated above, $20 \%$ of patients admitted to the unit are eventually proved not to have suffered a myocardial infarction. If this rate became lower, one would feel that occasional patients with infarcts would be misdiagnosed to their detriment. The deliberate policy also speeds up admission of patients to the unit as the Casualty Officers do not have to spend time establishing a firm diagnosis. This has proved satisfactory to both the unit and the Accident and Emergency Department.

\section{Acknowledgments}

I wish to thank the Physicians of Westminster Hospital in general under whose care these patients were admitted, and Dr C. J. Gavey in particular for his encouragement, also the British Heart Foundation for a personal grant during 1967. I thank also the Governors' Discretionary Fund of Westminster Hospital and Mr Charles Drew, who provided financial support. Her Majesty's Coroner for Westminster kindly gave me permission to use some of his mortality figures.

\section{References}

AsHFIELD, R.P. (1969). To be published.

AshField, R.P. \& GAVEY, C J. (1969). To be published.

Balcon, R., Hoy, J. \& Sowton, E. (1968) Haemodynamic effects of rapid digitalisation following acute myocardial infarction. Brit. Heart J. 30, 373.

Brown, K.W.G., MacMillan, R.L., Forbath, N., MeliGRANA, F. \& SCOTT, J.W. (1963) Coronary unit. Lancet, ii, 349.

DAY, H.W. (1963a) An intensive coronary care area. Dis. Chest, 44, 423.

DAY, H.W. (1963b) Preliminary studies of an acute coronary care area. J. Lancet, 83, 53.

DAY, H.W. (1965) Effectiveness of an intensive coronary care area. Amer. J. Cardiol. 15, 51.

Fluck, D.C. \& Burgess, P.A. (1966) A pressure stud electrode for continuous monitoring of the electrocardiogram. Lancet, i, 1405.

Goble, A.J., Sloman, G. \& Robinson, J.S. (1966) Mortality reduction in a coronary care unit. Brit. med. J. 1, 1005.

HANDLEY, A.J. (1967) Heparin administration by constant infusion pump. Brit. med. J. 1, 482.

Honey, G.E. \& TRuelove, S.C. (1957) Prognostic factors in myocardial infarction. Lancet, 1, 1155; 1209.
JewitT, D.E., Kishon, Y. \& Thomas, M. (1968) Lignocaine in the management of arrhythmias after acute myocardial infarction. Lancet, i, 266.

Julian, D.G., Valentine, P.A. \& Miller, G.G. (1964a) Disturbances of rate, rhythm and conduction in acute myocardial infarction. Amer. J. Med. 37, 915.

Julian, D.G., Valentine, P.A. \& Miller, G.G. (1964b) Routine electrocardiographic monitoring in acute myocardial infarction. Med. J. Aust. 1, 433.

Kimball, J.T. \& Killip, T. (1968) Aggressive treatment of arrhythmias in acute myocardial infarction: procedures and results. Progr. cardiovasc. Dis. 10, 483.

LASSERS, B.W. \& JuliaN, D.G. (1968) Artificial pacing in management of complete heart block complicating acute myocardial infarction. Brit. med. J. 2, 142.

LaWrie, D.M., Greenwood, T.W., Goddard, M., Harvey, A.C., Donald, K.W., Julian, D.G. \& Oliver, M.F. (1967) A coronary care unit in the routine management of acute myocardial infarction. Lancet, ii, 109.

Lown, B., Fakhro, A.M., Hood, W.B., JR \& Thorn, G. (1967) The coronary care unit. New perspectives and directions. J. Amer. med. Ass. 199, 188.

MacDonald, H.R., Rees, H.A., Muir, A.L., Lawrie, D.M., Burton, J.L. \& Donald, K.W. (1967) Circulatory effects of heroin in patients with myocardial infarction. Lancet, $\mathbf{i}$, 1070.

McNicol, M.W., Kirby, B.J., Bhoola, K.D., Everest, M.E., Price, H.V. \& Freedman, S.F. (1965) Pulmonary function in acute myocardial infarction. Brit. med. J. 2, 1270.

Pantridge, J.F. \& Geddes, J.S. (1967) A mobile intensive care unit in the management of myocardial infarction. Lancet, ii, 271.

Peel, A.A.F., Semple, T., Wang, I., Lancaster, W.M. \& DALL, J.L.G. (1962) A coronary prognostic index for grading the severity of infarction. Brit. Heart J. 24, 745.

Pentecost, B.L., Mayne, N. \& Lamb, P. (1967) Organization of a coronary care unit in a general hospital. Brit. med. J. 3, 298.

Pentecost, B.L. \& Mayne, N.M.C. (1968) Results of a general hospital coronary care service. Brit. med. J. $1,830$.

Rees, H.A., Muir, A.L., Macdonald, H.R., Lawrie, D.M., Burton, J.L. \& Donald, K.W. (1967) Circulatory effects of pethidine in patients with acute myocardial infarction. Lancet, ii, 863.

Restieaux, N., Bray, C., Bullard, H., Murray, M., Robinson, J., Brigden, W. \& MCDonald, L. (1967) 150 patients with cardiac infarction treated in a coronary unit. Lancet, i, 1285.

RoBINSON, J.S. (1965) Continuous electrocardiographic monitoring in acute myocardial infarction. Amer. Heart $J$. 69, 285.

Scott, M.E., Geddes, J.S., Patterson, G.C., Adgey, A.A.J. \& PANTRIDGe, J.F. (1967) Management of complete heart block complicating acute myocardial infarction. Lancet, ii, 1382.

Spracklen, F.H.N., Kimerling, J.J., Besterman, E.M.M. \& LitchFielD, J.W. (1968) Use of lignocaine in treatment of cardiac arrhythmias. Brit. med. J. 1, 89.

Thomas, M., Malmcrona, R., Fill.more, S. \& ShillingFORD, J.P. (1965) Haemodynamic effects of morphine in patients with acute myocardial infarction. Brit. Heart J. 27, 863.

Thomas, M. \& Woodgate, D. (1966) Effect of atropine on bradycardia and hypotension in acute myocardial infarction. Brit. Heart J. 28, 409.

Thomas, M., Jewitt, D.E. \& Shillingford, J.P. (1968) Analysis of 150 patients with acute myocardial infarction admitted to an intensive care and study unit. Brit. med. J. 1, 787. 